DOI https://doi.org/10.30525/978-9934-26-075-9-3

\title{
OPTIMIZATION OF THE LOWER EXTREMITIES TROPHIC ULCERS TREATMENT
}

\author{
Baranova I. V. \\ $M D, P h D$, \\ Associate Professor at the Depatment of Physical \\ and Rehabilitation Medicine \\ National Pirogov Memorial Medical University
}

Iliuk I. A.

$M D, P h D$,

Associate Professor at the Depatment of Internal Medicine № 2, National Pirogov Memorial Medical University

\section{Postovitenko K. P. \\ $M D, P h D$,}

Associate Professor at the Depatment of Physical and Rehabilitation

Medicine Rehabilitation Medicine and Medical-Social Expertise

National Pirogov Memorial Medical University

Vinnytsya, Ukraine

Diabetes is one of the most important medical and social problems in the world. Widespread, severity and variety of complications, the need for constant monitoring of laboratory parameters and dependence on regular medication are among the specific characteristics of the disease [1, p. 739; 2]. A significant proportion of patients are people from 20 to 60 years, mainly from low and middle income countries [3, p. 17; 4, p. 113].

None of the many proposed methods and techniques for the treatment of chronic wounds satisfies practical surgeons completely due to a recurrence rate has also become high $[2 ; 4$, p. $114 ; 5$, p. $34 ; 6$, p. 63].

The problem of blood circulation compensation is not solved only by drugs. In this regard, it is advisable to use a comprehensive treatment using modern rehabilitation methods, which include ozone therapy [6, p. 64; 7 , p. 2452; 8, p. 99]. Due to the use of different routes of ozonized oxygen mixture can significantly improve homeostasis and rheological properties of blood, the body's immune response, to overcome local oxidative stress. As a 
result, there is an intensification of reparative processes [4, p. 114-115; 5, p. 35-36].

The aim of the study was to optimize the treatment of chronic trophic ulcers of the lower extremities in patients with non-insulin-dependent diabetes mellitus by comprehensive treatment with ozone therapy.

Materials and methods. Under supervision were 52 patients with noninsulin-dependent diabetes mellitus in the stage of compensation and subcompensation, who were treated at the University Clinic of VNMU (Vinnytsya, Ukraine) during 2017-2019. In a prospective study, patients were distributed at the level of the number, corresponding to sex, duration of the disease on the state of carbohydrate metabolism, the main $(n=26)$ and the comparison group $(n=26)$. All patients were examined according to the generally accepted scheme [1, p. 740]. Trophic ulcers with 1-2 grade (MeggittWagner classification, 1981) were localized in typical places of the lower extremities, the period of their formation before treatment was from 8 to 12 weeks, the average area of ulcers was $8.2 \pm 2.1 \mathrm{~cm}^{2}$.

Pain in areas of trophic ulcers worried all patients. The intensity of pain correlated with the depth of trophic ulcers and the area of a lesion. The study design took into account the principles of the Declaration of Helsinki and the consent of patients to participate in the study. The combined method of ozone therapy was used in the study. In patients of the main group, intravenous administration of $200 \mathrm{ml}$ of $0.9 \% \mathrm{NaCl}$ sol with an ozone concentration of 12 $\mathrm{mg} / \mathrm{l}$ was alternated with local effects of chamber ozone therapy on the area of a trophic ulcer. Topical exposure was performed with an oxygen-ozone mixture with an ozone concentration of $20-15 \mathrm{mg} / \mathrm{l}$ for $20 \mathrm{~min}$ (the first procedures used the maximum concentration, with 5 procedures - the concentration was reduced). The number of procedures of general and local exposure was the same (10 procedures of each type), the total duration of treatment with ozone therapy -20 days. The procedures were started after removal of necrotized tissues and cleansing of wounds from purulent discharge. Drug therapy was performed according to the same plan in patients of the main and control groups [1, p. 745]. The latter involved the use of a questionnaire on the Quality of Life (SF-36), determining the size of trophic ulcers (planometric method by Kuleshov OV.) and the degree of marginal epithelialization (Popova LM., 1942). A rate of $>4 \%$ corresponds to rapid epithelialization and a good response to treatment, a rate of $<4 \%$ shows a slow rate of wound healing [9, p. 104].

Prior to treatment, the data of the SF-36 questionnaire in patients of the main and control groups were similar $(p>0.05)$ and significantly $(p<0.05)$ differed from the generally accepted population standard of urban residents 
aged $42 \pm 15.0$ years [11, p. 37]. The decrease in the indicators of the SF-36 questionnaire in the respondents was explained by the clinical symptoms of the disease, long-term ineffective treatment, limitation of physical and social functioning. Control parameters were evaluated in the main and comparison groups twice: before and on the 30th day of observation. The end point of the study was considered complete epithelialization of the trophic ulcer.

Results and discussion. All patients completed the treatment and received it positively. One month after the start of observation, the pain syndrome was significantly reduced in the group with conventional treatment and did not bother patients at all after complex treatment with combination ozone therapy. There was an increase in the area of fresh granulations to a greater extent in patients of the main group compared with patients in the control group in table 1.

Table 1 . The dynamics of a granulation area, epithelialization rate, and a size of diabetic ulcers in patients of the main $(n=26)$ and control $(n=26)$ groups at $30^{\text {th }}$ day of follow-up.

\begin{tabular}{|c|c|c|c|}
\hline Indicators & $\begin{array}{c}\text { Main group } \\
(\mathbf{n = 2 6})\end{array}$ & $\begin{array}{c}\text { Control group } \\
(\mathbf{n = 2 6})\end{array}$ & Difference \\
\hline $\begin{array}{c}\text { S of the granulations } \\
\text { (from the initial area of } \\
\text { the ulcer), } \%\end{array}$ & 95,2 & 31,8 & $63,4^{*}$ \\
\hline $\begin{array}{c}\text { The rate of } \\
\text { epithelialization, } \%\end{array}$ & $4,7 \pm 0,63$ & $2,4 \pm 0,92$ & $2,3^{*}$ \\
\hline $\begin{array}{c}\text { The average size of } \\
\text { trophic ulcers, } \mathrm{cm}^{2}\end{array}$ & $1,9 \pm 0,9$ & $4,6 \pm 1,2$ & $2,7^{*}$ \\
\hline
\end{tabular}

Notes: $*$ - significant difference of indicators, $\mathrm{p}<0,01$.

The area of granulations of the trophic ulcers in the main group differed in three times positively from the comparison group. The epithelialization rate was recorded in patients after the use of a combined laser therapy regimen more than in twice $(\mathrm{p}<0.01)$. As a result, the average size of trophic ulcers on the 30th day of complex treatment was more than in twice smaller in the main group in (Tab. 1.)

All persons who underwent treatment significantly improved their Quality of Life, especially in terms of a pain, a role activity, an emotional state, a physical functioning (Tab. 2).

Table 2. The Quality of Life indicators (SF-36 questionnaire) in patients of the main $(n=26)$ and in the control $(n=26)$ groups at $30^{\text {th }}$ day of follow-up. 


\begin{tabular}{|c|c|c|c|c|c|}
\hline Indicators & $\begin{array}{l}\text { Main } \\
\text { group } \\
(n=26)\end{array}$ & $\begin{array}{c}\text { Control } \\
\text { group } \\
(\mathbf{n}=26)\end{array}$ & $\begin{array}{c}\Delta O \text { between } \\
\text { indicators } \\
\text { of the main } \\
\text { group }(n= \\
26), \%\end{array}$ & $\begin{array}{c}\Delta K \text { between } \\
\text { indicators } \\
\text { of the } \\
\text { control } \\
\text { group }(\mathbf{n}= \\
26), \%\end{array}$ & $\Delta^{*}, \%$ \\
\hline $\mathrm{PF}$ & 50,44 & 42,61 & 38,91 & 21,15 & 17,76 \\
\hline $\mathrm{RP}$ & 51,31 & 42,93 & 59,59 & 42,93 & 30,33 \\
\hline BP & 52,70 & 49,33 & 62,55 & 49,57 & 13,47 \\
\hline GH & 51,32 & 47,31 & 36,81 & 28,11 & 8,7 \\
\hline VT & 54,32 & 50,17 & 22,86 & 12,11 & 10,75 \\
\hline SF & 54,37 & 50,31 & 12,91 & 4,79 & 8,12 \\
\hline $\mathrm{RE}$ & 55,29 & 49,70 & 44,96 & 31,09 & 13,87 \\
\hline $\mathrm{MH}^{*}$ & 57,32 & 57,03 & 1,61 & 1,46 & 0,15 \\
\hline
\end{tabular}

Note: $\Delta \mathrm{O}$ - the differences between the Quality of Life indicators in patients of the main group $(n=26)$ before and after the treatment were significant $(\mathrm{p}<0,01)$;

$\Delta \mathrm{K}$ - the differences between the Quality of Life indicators in patients of the control group $(n=26)$ before and after treatment were significant $(p<0,01)$;

$\Delta^{*}$ - the differences between the Quality of Life indicators in patients of the main and the control groups after the treatment were significant $(p<0,01)$;

$\mathrm{MH}^{*}$ - the dynamic of the indicator of "mental functioning" in the observation groups after treatment was unreliable $(p>0,01)$.

One month after the start of follow-up, the end point of the study was reached in the main group in $85 \%$ of patients versus $29 \%$ of patients in the comparison group $(\mathrm{p}<0.01)$.

The obtained data correspond to a positive assessment of the use of oxygen-ozonated mixture in the treatment of trophic ulcers of various origins [4, p. 114; 5, p. 36; 7, p. 2450]. All these works emphasize the positive effect of ozone therapy on the state of local immunity, bactericidal effect, regeneration of long-term non-healing wounds. The differences between the above methods are the concentration of the ozonated mixture, the number of procedures per course of treatment and the method of procedures.

Conclusions: Ozone therapy is an effective and appropriate addition to the comprehensive treatment of long-term non-healing trophic ulcers. A low cost, virtually no contraindications and the age restrictions, painless procedures with the possibility of the pathogenetic effects on chronic wound processes allow to recommend ozone therapy for widespread use during inpatient and outpatient treatment. 


\section{References:}

1. Brownrigg JR., Schaper NC., Hinchliffe RJ. (2015). Diagnosis and assessment of peripheral arterial disease in the diabetic foot. Diabet Med. 2015. № 32(6). P. 738-47. DOI:10.1111/dme.12749.

2. Jia L., Parker CN., Parker TJ., Kinnear EM. et al. Diabetic Foot Working Group, Queensland Statewide Diabetes Clinical Network (Australia). Incidence and risk factors for developing infection in patients presenting with uninfected diabetic foot ulcers. PLoS One. 2017. № 12(5). e0177916. DOI: 10.1371 /journal.pone.0177916.

3. Krisina OV. Trophic disorders of the soft tissues of the lower extremities in type 2 diabetes (review). Clin Endocrin \& Endocrin Surg. 2018. №1(61). P. 15-20. DOI: 10.24026/1818-1384.1(61).2018.126901.

4. Kushmakov R., Gandhi J., Seyam O., et al. Ozone therapy for diabetic foot. Med Gas Res. 2018. №8(3). P. 111-115. DOI:10.4103/20459912.241076.

5. Zhang J., Guan M., Xie C., Luo X. et al. Increased growth factors play a role in wound healing promoted by noninvasive oxygen-ozone therapy in diabetic patients with foot ulcers. Oxid Med Cell Longev. 2017. № 2(7). P. 32-37. DOI: $10.1155 / 2014 / 273475$.

6. Baranova IV., Bezsmertnyi YA., Bezsmertnaya HV. et al. Analgetic effect of ozone therapy: myths of reality? Pol Ann Med. 2020. №27(1). P. 62-67. DOI: 10.29089/2020.20.00099.

7. Song M., Zeng Q., Xiang Y., Gao L. et al. The antibacterial effect of topical ozone on the treatment of MRSA skin infection. Molecular medicine reports. 2018. №17. P. 2449-2455. DOI:10.3892/mmmr.2017.8148.

8. Karatieieva S., Muzyka N., Semenenko S., Bakun O. et al. Ultrastructural changes of wound macrophages under the influence of intravenous ozone therapy in patients with Diabetes and Inflamatory processes of soft tissues. Georgian Med News. 2018. № 2(276). P. 98-101.

9. Savchenko U.P., Fedosov S.R. (2007). Methods for determining the size of the wound surface. Herald of Surg. 2007. №166(1). P. 102-105.

10. Ivanova Yu.V., Klimova A.M., Korobov A.M. Treatment of trophic ulcers in patients with chronic venous insufficiency using phototherapy and modern wound coatings. Health of Ukraine. Thematic issue "Surg, Orthop, Trauma, Intensive care". 2019. № 2 (36). P. 5-9.

11. Armidzhanova VN., Goriachev DV., Korshunov NI. Population Quality of life indicators by SF-36 questionare (Results of multicenter study of quality of life «MIRAG». Science-Practical Rheum. 2008. № 1. P. 36-48. 